\title{
Ironizando con el antisemitismo: Respuestas del semanario Mundo Judío al Partido Nacional Fascista de Chile (1938-1940) ${ }^{1}$
}

Being Ironic with Antisemitism: Responses of the weekly paper Mundo Judio to the Chilean Partido Nacional Fascista (1938-1940)

\author{
Mg. Gustavo Guzmán Castro \\ gu.guzman@gmail.com \\ Universidad de Chile \\ Chile
}

\section{Resumen}

Durante los años treinta del siglo pasado, se produjo en Chile una proliferación de agrupaciones nacionalistas de derecha contrarias al liberalismo, la democracia y el comunismo. En algunos casos, tales agrupaciones adoptaron también el fascismo y el antisemitismo provenientes de Europa, desarrollando campañas antijudías inéditas en la Historia de Chile. El presente artículo indaga en las respuestas del semanario Mundo Judío, principal órgano de prensa de la colectividad judía chilena de los años treinta, frente al antisemitismo del Partido Nacional Fascista (PNF) de Raúl Olivares Maturana, el grupo fascista chileno más radical de los años treinta, destacando diferencias respecto de cómo se había enfrentado las provocaciones antisemitas del fascismo chileno en los años previos.

Palabras clave: Antisemitismo en Chile - Mundo Judío - Partido Nacional Fascista de Chile - Prensa sionista de Chile

\footnotetext{
Abstract

During the thirties many right-wing nationalist groups appeared in Chile. Most of them declared to be against Liberalism, Democracy and Communism. In some cases these groups

${ }^{1}$ El presente artículo sintetiza parte de los capítulos 8 y 9 de "La patria sin judíos: Antisemitismo nacionalista en Chile, 1932-1940. Los casos del Movimiento Nacional Socialista y del Partido Nacional Fascista", tesis para acceder al grado de Magíster en Historia, mención Historia de Europa, de la Universidad de Chile.
} 
also embraced the Fascism and the Antisemitism coming from Europe, developing antiSemitic campaigns, unprecedented in the Chilean History. This article enquires in the responses of the weekly paper Mundo Judio, main press publication of the Chilean Jewish community during the thirties, to the Antisemitism of the Raúl Olivares Maturana's Partido Nacional Fascista, the most radical Chilean fascist group of the period, distinguishing differences with the former responses to Chilean fascism.

Key words: Antisemitism in Chile - Mundo Judio - Chilean Partido Nacional Fascista Chilean Zionist press

A comienzos de junio de 1939, seis meses después de la llegada del Frente Popular al gobierno y nueve meses después de la Matanza del Seguro Obrero -cuando un grupo de militantes del Movimiento Nacional Socialista de Chile (MNS) intentó un golpe de estado que terminó con casi todos ellos ejecutados in situ por Carabineros, con el MNS disuelto y con las posibilidades de triunfo del candidato presidencial oficialista, Gustavo Ross Santa María, fuertemente dañadas- el joven Partido Nacional Fascista de Chile publicó el primer número de su semanario, La Patria. El titular de primera plana, que además daba nombre al artículo principal de aquel primer número, echaba luces sobre las prioridades ideológicas que tendría esta publicación durante sus meses de vida: “¿Existe el judaísmo en Chile?”. Allí se abordaba el "problema judío, que aunque se pretenda negar, su existencia es manifiesta en nuestro país". Según este grupo de fascistas, que menos de un año antes se había escindido del MNS de Jorge González von Marées acusándolo de alejarse de los principios básicos del fascismo, "la presencia de elementos judíos" había comenzado a sentirse en Chile a comienzos del siglo XX, cuando "estos elementos, dedicados al comercio, introdujeron entre nuestras clases modestas y asalariadas la costumbre de las famosas ventas al semanal"; no obstante el entusiasmo inicial por esta modalidad de compra, "los obreros comenzaron a ver claro, y el negocio no era tan ventajoso como muchos se lo imaginaban por cuanto (...) con el valor convenido se pagaba cinco veces su 
costo", lo que habría comenzado "a hacerlos antipáticos a ojos de muchos, que veían en ellos a mercaderes que especulaban pingüemente con las necesidades de los obreros". Así habría comenzado, según La Patria, el rechazo de los chilenos por los inmigrantes judíos, rechazo agravado por "la intromisión de elementos de ascendencia judía que hacían propaganda revolucionaria y contraria a nuestras modalidades, desde centros u organismos políticos de marcada tendencia comunista" y por la llegada al país de "literatura extranjera en que se develaban los planes político-sociales puestos en práctica por los judíos en otros países”, en referencia a los Protocolos de los Sabios de Sión. Este primer artículo de La Patria concluía denunciando "las nacionalizaciones de ciudadanos extranjeros a granel, sobresaliendo entre estos 'nuevos chilenos' un enorme porcentaje de elementos judíos", así como el hecho de que hubiera "en el Parlamento numerosos judíos nacionalizados". Ello dejaba entrever "la influencia de los elementos semitas en las distintas actividades de nuestro país", logrando "traspasar a sus manos gran parte del poder comercial y llegar a dejar sentir su influencia hasta en las esferas de Gobierno, donde tienen destacados a muchos de su raza" (La Patria, 2 mayo 1939, p. 1).

Manifestaciones antisemitas como ésta, inexistentes en Chile hasta comienzos de los años treinta, se repetirían sistemáticamente en cada una de las veintiocho ediciones de La Patria, entre junio de 1939 y marzo de 1940, dotando al PNF de un perfil ideológico similar al de sus pares europeos, basado en un novedoso y radical antisemitismo. El presente artículo indaga en las reacciones que tales expresiones suscitaron en el semanario Mundo Judío, publicación oficial de la Federación Sionista de Chile y principal órgano de prensa de la colectividad judía chilena de la época, para lo cual ha sido dividido en tres partes. La primera da cuenta de la bibliografía o el estado de la cuestión sobre el PNF; la segunda se centra en el antisemitismo de este partido, expresado principalmente en las páginas del semanario La Patria; por último, la tercera parte expone las principales reacciones de Mundo Judío frente al antisemitismo del PNF, distinguiendo importantes diferencias respecto de cómo el mismo semanario sionista había enfrentado los ataques del MNS, antecesor directo del PNF. 


\section{La bibliografía sobre el Partido Nacional Fascista de Chile}

A diferencia de la bibliografía dedicada a sus antecesores nacistas ${ }^{2}$ (Edwards Vives y Frei Montalva, 1949; Pike, 1963; Bicheno, 1972; Potashnik, 1974; Fontaine, 1974; Ramírez Necochea, 1978; Grugel, 1985; Sznajder, 1990, 1992; Etchepare y Stewart, 1995; Deutsch, 1996, 2005) los estudios sobre el Partido Nacional Fascista de Chile, principal agrupación fascista chilena de fines de los años treinta, son muy escasos, limitándose a los trabajos de Verónica Valdivia $(1993,1995)$ y Marcus Klein $(2000,2001)$.

En el primero de sus trabajos sobre los grupos nacionalistas nacidos del quiebre del MNS, Valdivia (1993) plantea tres ideas que merecen ser destacadas a la luz de nuestro estudio. En primer lugar, que la llegada del Frente Popular a la Presidencia de la República, a fines de 1938, constituye un factor fundamental para comprender el surgimiento de grupos fascistas como el PNF. Según Valdivia, la derecha, en general, habría tenido importantes dificultades para asumir su derrota electoral, adoptando una postura de abierta oposición al nuevo gobierno; los grupos nacionalistas herederos del MNS, en particular, habrían desconocido "por completo" el triunfo frentista, "luchando por su destitución y la destrucción del orden democrático-liberal que había permitido su ascenso". De esta manera, el triunfo de Aguirre Cerda habría hecho que se reprodujera en Chile la polarización ideológica europea entre fascismos y democracias: la defensa del orden político existente fue encabezada por el Frente Popular, mientras que "la línea pro-totalitaria fascistoide fue adoptada por los grupos de tendencia nacionalista que habían madurado durante la década de 1930" (Valdivia, 1993, pp. 119-20) en el seno del MNS, como el PNF. En segundo lugar, la semejanza ideológica del PNF respecto de sus símiles europeos, semejanza que se explicaría por los éxitos de las potencias fascistas europeas en los años previos a la Segunda Guerra Mundial, los que habrían encandilado al fascismo chileno. Sería esta ligazón ideológica con el fascismo europeo, más que acciones de espionaje o de colaboración propiamente tales, las que explicarían las permanentes acusaciones en contra

\footnotetext{
${ }^{2}$ Recordemos que para diferenciarse del nazismo alemán, los miembros del Movimiento Nacional Socialista de Chile, liderado por Jorge González von Marées, se hacían llamar "nacistas”, con ce.
} 
del PNF de formar la "Quinta Columna" en Chile (Valdivia, 1993, pp. 127-30). Y, en tercer lugar, la marginalidad política del PNF. Según la autora, pese a todos sus esfuerzos el partido encabezado por Raúl Olivares Maturana "no dejó de ser marginal” ni logró "atraer los militantes suficientes como para convertirse realmente en un movimiento nacional". Las razones se encontrarían en la polarización ideológica de la política chilena de fines de los años treinta: la robustez de la derecha tradicional y la intransigencia ideológica del PNF habrían confinado a éste último a los márgenes de la escena política, a la extrema derecha, impidiendo que se acercara a la derecha tradicional, "único tronco que podía haberlo fortalecido" (Valdivia, 1993, pp. 130-1).

En su segundo trabajo sobre los grupos nacionalistas de los años del Frente Popular, Valdivia (1995) destaca la importancia del contexto político internacional en el nacimiento y desarrollo de grupos como el PNF. En este sentido, cree que el estallido de la Segunda Guerra Mundial y la crisis del capitalismo habrían creado "condiciones históricas favorables al desarrollo de tendencias anti-internacionalistas y nacionalistas" a nivel mundial. No obstante, al momento de nacer el PNF, a fines de los años treinta, habían comenzado a "debilitarse las figuras de Hitler y Mussolini, al iniciarse su seguidilla de fracasos", cuestión que limitó su crecimiento y facilitó la acción de los grupos antifascistas y de los medios de comunicación de izquierda que exigían acciones gubernamentales en contra del PNF (Valdivia, 1995, pp. 6-10, 20). Sería esta estrecha identificación ideológica del PNF con el fascismo europeo, crecientemente desacreditado, una de las principales causas de su fracaso. A ojos de la opinión pública chilena de fines de los años treinta, suficientemente informada de la situación europea y de la violencia nazi, la defensa irrestricta que el PNF hacía de Berlín y Roma resultaba a todas luces negativo, aislándolo. Sin embargo, esta no es la única razón esgrimida por Valdivia para explicar el fracaso del partido de Olivares Maturana. A esta causa principal añade la neutralización del "peligro de subversión izquierdista" (Valdivia, 1995, p. 48) en el Chile de fines de década, que minó sus posibilidades de crecimiento sobre la base de una alianza con la derecha tradicional. 
Reconocemos el papel de Valdivia como precursora en el estudio de los grupos nacionalistas nacidos tras el quiebre del MNS y concordamos con ella en las razones detrás del fracaso del PNF. En este sentido, no cabe duda que tanto el creciente descrédito internacional del fascismo, sumado a la polarización de la política chilena de la época -con una derecha tradicional robusta, que no necesitaba del apoyo de una extrema derecha fascista - y la intransigencia ideológica del propio PNF condenaron a éste a una posición de marginalidad y al fracaso. No obstante, el trabajo de esta autora merece un par de observaciones. La primera, que los grupos estudiados por ella no son sólo nacionalistas, sino específicamente fascistas, como plantea Marcus Klein (2000), según veremos más adelante. La segunda, más importante desde el punto de vista de este trabajo, su inexplicable falta de interés por el antisemitismo del PNF -elemento ideológico fundamental del proyecto fascista de tercera vía y fenómeno político-cultural ineludible a la hora de tratar el período histórico de Entreguerras-, como quedará claro en las siguientes páginas.

Del mismo modo, creemos que de los trabajos de Marcus Klein (2000, 2001) sobre los fascismos del Cono Sur de los años treinta y cuarenta se desprenden importantes conclusiones con vistas a nuestro estudio. En primer lugar, Klein destaca el interés académico que se produjo en la década del noventa por el fascismo chileno de entreguerras, en particular por el MNS, aunque constata la existencia de un vacío académico respecto de los grupos nacidos tras su quiebre. La excepción a este vacío la constituye Verónica Valdivia y sus trabajos sobre las "nuevas voces del nacionalismo chileno", recién mencionados $(1993,1995)$. A diferencia de la historiadora chilena, Klein considera que esas "nuevas voces" no sólo fueron nacionalistas, sino específicamente fascistas. Ello porque el término "nacionalista" no connotaría una posición ideológica distintiva, considerando que durante los años treinta y cuarenta del siglo pasado distintos partidos asumieron posturas que pueden ser descritas como tales, poniendo como ejemplos los programas económicos propugnados por los partidos Socialista y Comunista. Por ello, la caracterización del PNF como "nacionalista" es insuficiente, pues soslaya su especificidad ideológica. Indudablemente el PNF - como antes el MNS- basó su discurso en el 
nacionalismo, pero desarrolló una "forma revolucionaria de ultra-nacionalismo" característica de los movimientos fascistas, pregonó la necesidad de un "renacimiento" que revirtiera la decadencia de la nación y le diera grandeza, así como el establecimiento de un nuevo orden totalitario que trascendiera el capitalismo liberal y el estatismo comunista y que uniera en su seno a todas las clases sociales organizadas jerárquicamente en una comunidad nacional. Todo lo anterior lleva a que Klein concluya que se trató en realidad de agrupaciones propiamente fascistas, y no simplemente nacionalistas, idea que compartimos plenamente (Klein, 2001, pp. 347-8).

En segundo lugar, Klein coincide con Valdivia en que el PNF, como el resto de los grupos surgidos tras el colapso del MNS - principalmente la Vanguardia Popular Socialista (VPS) y el Movimiento Nacionalista de Chile (MNCh)-, fracasó en conseguir un número significativo de seguidores y en convertirse en un movimiento de masas, aunque planteando un matiz respecto de la importancia del contexto internacional en el fracaso del PNF. Para Klein, las causas nacionales se encontrarían en la fuerza de la derecha tradicional y en la polarización del sistema político chileno, que limitaron el espacio político en el que podía desenvolverse un partido como el PNF, impidiendo que encontrara su "nicho" propio, idea que compartimos plenamente; las razones internacionales, por su parte, habrían crecido en importancia a partir del estallido de la Segunda Guerra Mundial, haciendo que la pretensión del PNF de representar soluciones nacionales para los problemas de Chile perdiera credibilidad. Asimismo, las posiciones ideológicas defendidas por el fascismo se convirtieron a ojos de la opinión pública en radicales e impopulares. Por otro lado, el miedo a eventuales planes imperialistas del Tercer Reich en América Latina hizo que un grupo como el PNF, férreamente alineado con Alemania e Italia, fuera acusado permanentemente de formar la Quinta Columna del fascismo europeo en Chile. Vale decir, con el estallido de la guerra -y a medida que ésta se fue desarrollando- el fascismo perdió su prestigio como referente de solución a los problemas nacionales, condenando así, las aspiraciones de crecimiento del PNF (Klein, 2001, p. 349). 
En tercer lugar, Klein destaca que mientras la VPS intentó hacerse de un espacio junto a la izquierda democrática, el PNF tomó la causa del fascismo en Chile e intentó ocupar el espacio dejado por el MNS en el espectro político. En este sentido, Klein cree que la razón que llevó al partido de Olivares Maturana a adoptar el nombre de Partido Nacional Fascista habría sido el deseo de enfatizar la naturaleza fascista del grupo y disipar así cualquier eventual desvío del fascismo europeo, como el experimentado por el MNS. En tal sentido, no cabe duda que el PNF quiso destacar desde un principio las diferencias con su antecesor, las que se reflejaron en su negativa a participar de procesos eleccionarios -salvo para apoyar la candidatura de Ross Santa María en contra de la de Aguirre Cerda- y en su “inflexible antisemitismo" (Klein, 2001, p. 354).

En cuarto lugar, Klein considera que el PNF constituyó un "fenómeno político efímero", incapaz de trascender el pequeño círculo compuesto por ex nacistas ardientemente antisemitas. De forma reveladora, el partido liderado por Raúl Olivares Maturana nunca fue capaz de atraer a los nacistas de alto nivel que dejaron el MNS una vez que éste se convirtió en VPS, como Carlos Keller y Raúl Valdivieso. Entre las razones del fracaso del PNF Klein considera su estrecha identificación con el Tercer Reich, el cual habría minado sus esfuerzos de atraer a un número significativo de seguidores, y su virulento antisemitismo, que si bien atrajo a ex militantes nacistas también condenó al PNF a un lugar de marginalidad y de extrema derecha (Klein, 2001, p. 359).

El desarrollo del fascismo chileno durante la presidencia de Aguirre Cerda, concluye Klein, se caracterizó por una declinación continua. A pesar de que el Frente Popular estaba en el poder, el PNF no fue capaz de capitalizar la existencia de un enemigo tangible y dar fuerza a su causa. Asimismo, la persistente fortaleza de la derecha tradicional y la polarización del sistema político limitaron el espacio político de las fuerzas de extrema derecha, minando de manera crucial su esfuerzo por hacerse de un nicho político propio. Los pactos electorales con la oposición conservadora -exitosos en atraer a sectores anticomunistas- ponen de manifiesto las dificultades que los grupos fascistas enfrentaron en este período. Además de los factores internos recién mencionados, Klein atribuye gran importancia al desarrollo de 
la esfera internacional para explicar el fracaso del PNF en convertirse en un movimiento de masas. Este aspecto está ligado, según él, al cambio de percepción respecto del fascismo a partir de septiembre de 1939. Desde entonces, el fascismo fue asociado con asesinatos masivos, campos de concentración y visto como una amenaza a la independencia y soberanía nacionales, condenando a grupos como el PNF (Klein, 2001, pp. 374-5).

Sin dudas, las conclusiones de Marcus Klein sobre el PNF suponen un importante aporte al estudio del fascismo chileno de los años treinta, sin embargo nos parece que incurre en un error metodológico similar al de Valdivia: no someter el contenido de La Patria a un análisis formal. De haberlo hecho, se habría percatado de la utilización de material propagandístico antisemita -textos y caricaturas- de evidente origen alemán, que difícilmente pudieron llegar a manos de los editores de un semanario como La Patria sin algún grado de colaboración de agentes alemanes, y de la colaboración del semanario fascista chileno con otras publicaciones antisemitas argentinas y uruguayas, como veremos más adelante.

\section{El antisemitismo del Partido Nacional Fascista de Chile (1938-1940)}

A pesar de la centralidad ideológica que el antisemitismo tuvo para el PNF, Valdivia no le concede la importancia que merece ni lo somete a análisis en sus trabajos sobre el nacionalismo chileno de los años del Frente Popular (1993, 1995). Aunque destaca el vínculo que para los fascistas chilenos existía entre antisemitismo y anticomunismo, así como el rechazo a la inmigración judía, la autora no profundiza en estos temas, limitando el alcance de sus conclusiones. Y aunque su análisis del antisemitismo del PNF es más profundo que el de Valdivia, dándole una importancia más acorde a lo que las mismas fuentes sugieren, Klein $(2000$, 2001) tampoco aquilata completamente su importancia ideológica. Aunque reconoce que el inflexible antisemitismo del PNF, además de su negativa a participar de procesos eleccionarios, marcaría una importante diferencia ideológica del partido de Olivares Maturana respecto del MNS, no profundiza mayormente en las características del antisemitismo del PNF, ni en cómo representaban a los judíos, ni 
las consecuencias políticas y culturales de tales representaciones, ni el origen del material propagandístico antisemita utilizado por La Patria, ni mucho menos la respuesta de la colectividad judía chilena de la época frente a la campaña antisemita del PNF.

La ausencia del PNF y de su campaña antisemita en los reportes que la representación diplomática alemana en Chile envió a Berlín, induce a Klein a menospreciar la importancia que este antisemitismo tuvo para el fascismo chileno de los años treinta. ¿Qué habría motivado, entonces, a que el PNF desarrollara una campaña antisemita tan virulenta y sistemática? Cuando menos, ¿qué ayudaría a explicar tal decisión? Para el autor, en ello habría influido el creciente número de inmigrantes judíos llegados desde Europa a lo largo de los años treinta y el auge del antisemitismo en Europa, en especial desde que el régimen de Mussolini instauró política antijudías similares a las alemanas en 1938. En esa línea, no sería de extrañar que la decisión de adoptar semejante discurso antisemita se hubiera basado en el deseo de subrayar la cercanía ideológica del PNF con la potencia fascista dominante, la Alemania nazi (Klein, 2001, pp. 356-8).

Respecto de una posible vinculación del PNF con los países del Eje, en particular con Alemania, y de un eventual financiamiento internacional, Klein afirma que no se han podido encontrar pruebas que lo confirmen (Klein, 2001, p. 358). Sin embargo, la publicación de un texto como el "Talmud (Schuljan Aruj)" en las páginas de La Patria, así como de otros textos y caricaturas antisemitas de evidente origen europeo, ponen en entredicho la seguridad con que Klein rechaza eventuales nexos entre el PNF y agentes nazis alemanes. En el mismo sentido, Klein soslaya la colaboración de La Patria con importantes publicaciones antisemitas argentinas -Crisol, Clarinada- y uruguayas Atención-(Guzmán Castro, 2012, pp. 143-155).

Por último, Klein plantea que el radical antisemitismo del PNF habría colaborado significativamente a su fracaso. Según él, el partido de Olivares Maturana habría sido incapaz de trascender el pequeño círculo de ex nacistas fanáticamente antisemitas y de sobrellevar la carga que significaban su estrecha identificación con el Tercer Reich. 
Aunque en primera instancia el "virulento antisemitismo" del PNF logró atraer a ex miembros del MNS a sus filas, a la larga alejó a otros derechistas y nacionalistas con afinidades ideológicas al fascismo (Klein, 2001, p. 359).

Los resultados de nuestra investigación (Guzmán Castro, 2012) sugieren que el radical antisemitismo contenido en las páginas de La Patria constituyó el elemento ideológico más importante del Partido Nacional Fascista de Chile. De manera mucho más sistemática y virulenta que las publicaciones nacistas, el semanario del PNF representó a los judíos como un colectivo de comerciantes ávidos e inescrupulosos, inventores y dominadores del capitalismo internacional, que no descansaría hasta conseguir el dominio mundial. Recurrentemente, los acusó de apropiarse de las riquezas chilenas, de la administración pública, de las profesiones liberales, de los tradicionales negocios del centro de Santiago, entre otras cosas. Asimismo, los acusó de inventar y dominar en su beneficio el comunismo, la masonería, el cine, la trata de blancas, y otros elementos propios de la modernidad. En tal sentido, no cabe duda que la influencia de los Protocolos de los Sabios de Sión fue mayor en el PNF que en el MNS, y, sobre todo, que la utilización política de esta "superstición política" fue más importante en el primero que en el segundo (Guzmán Castro, 2012, pp. 164-72).

No obstante las similitudes entre los discursos antisemitas del MNS y el PNF, existen elementos de La Patria que lo distinguen de las publicaciones nacistas. Para el semanario fascista, los judíos no sólo eran prestamistas usureros y agitadores comunistas sino también narcotraficantes, estafadores y proxenetas que, con su acción, amenazaban la integridad de Chile. Por ello los consideró incompatibles con ocupaciones más nobles, como la agricultura y la milicia, llamando a su exclusión absoluta de ellas. Del mismo modo, La Patria se mostró más persistente que las publicaciones nacistas en su denuncia de una "invasión judía". Creemos que ello no es atribuible únicamente al considerable aumento de la inmigración judía al país a fines de los años treinta, como sugiere Klein, ni a los conflictos sociales que tal inmigración -como cualquier otra- pudiera suscitar, sino a opciones ideológicas específicas, tomadas del fascismo europeo. La Patria presentó 
permanentemente la llegada de judíos a Chile en términos de "amenaza" e "invasión", llegando al punto de afirmar que el país se estaba convirtiendo en "la Palestina de Sudamérica”. En tal sentido, no es de extrañar sus incesantes alegatos en contra de la nacionalización de judíos y de su ingreso en la administración pública y las fuerzas armadas, dada la pretendida incompatibilidad entre judaísmo y chilenidad sostenida por el PNF. Según La Patria, la influencia judía en la sociedad chilena llegaba a tal punto que toda la política nacional se encontraba subordinada a los intereses particulares del judaísmo, como supuestamente probaban la influencia de la empresa minera Hochschild y la instalación de la fábrica de zapatos Bata (Guzmán Castro, 2012, pp. 137-60).

Esta persistente campaña en contra de la inmigración judía hizo que el affaire de las coimas cobrara particular importancia para el PNF. Salido a la luz pública a fines de 1939, el escándalo por el pago de coimas para conseguir visados de ingreso a Chile favoreció un ambiente hostil a los inmigrantes judíos que se tradujo en el cese de esta inmigración a comienzos de 1940 (Nes-El, 2009). Sin embargo, el PNF fue incapaz de capitalizar dicho ambiente en su favor, encabezando el descontento generalizado en contra del rol de algunos judíos involucrados en el negociado y fortaleciendo su posición específica dentro de la derecha chilena. Ello pone de manifiesto el fracaso de la opción tomada por el PNF y de su intento por obtener un nicho propio sobre la base de un antisemitismo radical, intransigente y similar al desarrollado por el nazismo alemán.

En cualquier caso, existe una diferencia significativa entre los discursos antisemitas del MNS y el PNF que merece ser resaltada. Aunque La Patria no llegó a plantear que los judíos eran racialmente inferiores a los chilenos, sí afirmó que su rechazo a la inmigración judía se debía a una "cuestión de higiene y profilaxis", comparando su campaña antisemita con la acción de un médico que elimina las bacterias que amenazan la salud del cuerpo. Esta característica del antisemitismo del PNF no sólo debe ser vista como una cuestión formal, discursiva, pues tiene implicancias políticas más profundas. Tales afirmaciones, como muchas otras, alinearon al PNF con el nazismo alemán e intentaron movilizar a la opinión pública en contra de los judíos, culpándolos de la declaración de guerra británica en 
contra de Alemania y "limpiando" la imagen exterior del Tercer Reich. Aunque sin plantear una inferioridad racial judía respecto de los chilenos -cuestión que lo distingue del antisemitismo nazi alemán-, el PNF no dudó en referirse a los judíos que llegaban a Chile por esos días de "hez contagiosa", "gérmenes", "bacterias” y "parásitos”, etcétera (Guzmán Castro, 2012, pp. 137-60).

Si bien Klein destaca que no se ha podido encontrar evidencia documental que compruebe de manera irrefutable la colaboración del PNF con los países del Eje, no cabe duda que las posiciones adoptadas por el partido de Olivares Maturana respecto de la cuestión judía aunque no sólo respecto de ella- se alinearon siempre con las seguidas por Alemania e Italia, recurriendo para ello a material propagandístico de origen extranjero. En tal sentido, debemos decir que nuestra investigación (Guzmán Castro, 2012) pone en evidencia la inclusión de material propagandístico de origen alemán en las páginas de La Patria, cuestión soslayada tanto por Valdivia (1993, 1995) como por Klein (2000, 2001). Como muestran las fuentes, el semanario fascista no sólo editó artículos provenientes de importantes revistas antisemitas argentinas -como Crisol y Clarinada- y uruguayas -como Atención-sino también textos y material iconográfico de evidente origen nazi, que muy difícilmente pudieron haber llegado a manos de un pequeño partido de extrema derecha chilena sin la colaboración de agentes alemanes, como las secciones Talmud (Schuljan Aruj) y numerosas caricaturas. En tal sentido, creemos que el alineamiento del partido de Olivares Maturana con el Tercer Reich -en particular tras la expulsión de Voigt- no sólo se debió a la admiración de los fascistas chilenos por el régimen de Hitler, sino que pudo ser consecuencia de intereses más concretos (Guzmán Castro, 2012, pp. 143-68).

En vista de todo lo anterior, creemos que este antisemitismo secular de origen europeo adoptado por el PNF - distinto del antijudaísmo de origen cristiano, anterior al primeromanifiesta todos los rasgos distintivos del antisemitismo moderno. En primer lugar, representó permanentemente a los judíos como una "organización comercial internacional" y un "complejo familiar mundial con intereses idénticos en todas partes" que, como "fuerza secreta tras el trono", era sospechosa de "conspirar para la destrucción de todas las 
estructuras sociales" (Arendt, 2004, pp. 62-72). De manera más persistente y radical que el MNS, el partido de Olivares Maturana vio en los judíos a un colectivo anacional incompatible con la nacionalidad chilena que pretendía conseguir ni más ni menos que la dominación planetaria por medio del capitalismo, el comunismo y un sinfín de invenciones ya descritas, siguiendo la lógica del "mito del judío" contenida en los Protocolos de los Sabios de Sión. En segundo lugar, nuevamente de una manera mucho más persistente y radical que sus antecesores nacistas, el PNF justificó y promovió la exclusión efectiva de los judíos de la sociedad chilena. Sin necesidad de recurrir a categorías de inspiración biológica, el La Patria defendió la exclusión de los judíos de la sociedad debido a su "objetiva" nocividad, atestiguada por un sinfín de "pruebas". En palabras de Bauman, el PNF desarrolló una "estrategia de extrañamiento" en contra de la "categoría ofensora" representada por los judíos (Bauman, 1997, pp. 85-91). En tercer lugar, el antisemitismo del PNF intentó aprovechar aquel sentido común antijudío de la época -el "antisemitismo tradicional", en palabras de Gino Germani (1962)- para enunciar representaciones particularmente negativas respecto de los judíos, tomadas del repertorio antisemita europeo, y capitalizarlas políticamente en beneficio propio -un "antisemitismo ideológico" propiamente tal, diría Germani (1962)-. Apelando a este sentido común antijudío, el PNF intentó conseguir cierto grado de unanimidad social y política respecto de la supuesta nocividad judía, aunque sin éxito (Arendt, 2004, pp. 62-72). En cuarto lugar -y aquí radica el rasgo más importante del antisemitismo moderno de origen europeo desarrollado en Chile por el PNF-, este discurso fue utilizado no sólo para excluir a los judíos de la sociedad chilena, sino con otros fines políticos concretos, a saber, la construcción de un referente político fascista, el ataque al Estado liberal chileno y la defensa del Eje. Como señaló Arendt respecto del caso europeo, el antisemitismo del PNF no sólo se dirigió en contra de los judíos de carne y hueso, sino también contra el estado liberal y la democracia (Arendt, 2004, pp. 91-7) y, en el caso puntual de Chile, contra el Frente Popular y los partidos que lo formaban, a quienes acusó permanentemente de agrupación "judía" y "masona" interesada en la destrucción de la chilenidad. 
En síntesis, creemos que el antisemitismo del PNF intentó capitalizar un imaginario antijudío preexistente en el que los judíos ocupaban un lugar negativo, influido por el catolicismo y por la identificación de los judíos con el dinero, que en palabras de Germani (1962) cabría calificar como "antisemitismo tradicional". Sobre la base de dichas tradiciones antijudías, el PNF desarrolló un sistemático y radical antisemitismo de origen europeo, propiamente "ideológico", a través del cual no sólo atacó a los judíos mismos y a su inmigración a Chile sino también a sus adversarios políticos del Frente Popular, entonces en el gobierno, intentando así conseguir un espacio político e ideológico propio, de extrema derecha. Como sabemos, tal intento por construir una tercera vía fascista sobre la base del antisemitismo, así como la defensa del Eje, resultó un rotundo fracaso. Así, en mayo de 1940, apenas dos años después del comienzo del "desbande nacista" -cuando una porción importante de los militantes nacistas abandonaron el MNS acusando a González von Marées de traicionar la ideología fascista- que le había dado vida, el Partido Nacional Fascista de Chile desapareció por completo del escenario político chileno.

\section{Respuestas de Mundo Judio al antisemitismo del PNF (1938-1940)}

Como resumimos en otro lugar (Guzmán Castro, 2013), a comienzos de los años treinta Chile tenía una población poco mayor a los cuatro millones de habitantes, de los cuales no más de cuatro mil eran judíos. En su mayoría, eran askenazíes rusos y polacos, así como sefaradíes de Macedonia, Salónica y Turquía. Con la llegada de Hitler al poder, en 1933, la composición de esta pequeña colectividad comenzó a cambiar, dada la creciente llegada de askenazíes desde Europa central. Desde el punto de vista organizativo, no existía mayor unidad entre los grupos que componían la colectividad. Con excepción de la Federación Sionista -fundada en 1919, luego de la Declaración Balfour- no existía una institución central o unitaria que aglutinase al judaísmo chileno. Esta federación estaba compuesta mayoritariamente por jóvenes con estudios universitarios, en su mayoría nacidos en Chile o llegados en su infancia, que a diferencia de sus padres se mostraron políticamente muy activos. Fueron estos jóvenes quienes encabezaron la defensa del judaísmo de los ataques 
antisemitas provenientes del fascismo chileno -tanto del MNS como del PNF- y lo hicieron desde la tribuna ofrecida por la incipiente prensa comunitaria (Nes-El, 2009, pp. 51-5).

En general, la generación de judíos mayores se mostró reacia a participar activamente en política. Como suele suceder con los inmigrantes de primera generación, este grupo poco asimilado se abocó a sus labores privadas y se reunió con sus pares en actividades sociales y religiosas. En el caso puntual de los askenazíes, éstos publicaron dos semanarios en yiddish, El Semanario Israelita de Chile y La Prensa Israelita, publicaciones que informaban preferentemente sobre las actividades sociales y religiosas del grupo de habla yiddish pero que no intentaron influir en la opinión pública chilena, dada la opción lingüística recién señalada (Guzmán Castro, 2013, p. 59).

Desde el punto de vista de la generación de judíos jóvenes, la publicación de prensa más importante de comienzos de los años treinta fue la revista Nosotros, dirigida por el futuro diputado socialista Natalio Berman. Tras su desaparición, en 1934, dicho lugar fue ocupado por el semanario Mundo Judío, publicación oficial de la Federación Sionista de Chile y uno de los órganos de prensa más importantes de la historia del judaísmo chileno. A diferencia de El Semanario Israelita de Chile y La Prensa Israelita, Mundo Judío se publicaba en español, era vendido en quioscos y tenía un tiraje relativamente alto, lo que le permitió ser leído también por un público no judío y alcanzar una considerable influencia en la opinión pública de la época (Nes-El, 2009, p. 55).

En su primer número, aparecido los primeros días de 1935, Mundo Judío declaró tener una doble finalidad. La primera, "informar sobre todo lo que ocurre en la vida judía a través del mundo", en particular sobre la situación de los judíos en Alemania, donde los nazis "han convertido el antisemitismo en sistema de gobierno". La segunda, defender a los judíos orientando a "la opinión pública del país frente a los ataques que se hagan del judaísmo". Al respecto, el semanario sionista adelantaba que impediría que se "envenenen las almas jóvenes de América con informaciones malévolas sobre nuestra existencia” (Mundo Judio, 3 enero 1935 , p. 3). 
La importancia de esta segunda finalidad de Mundo Judio quedó de manifiesto durante todo 1935, primer año de vida del semanario sionista. Así vemos que apenas un mes después de su aparición, respondió a las acusaciones nacistas en contra del "judaísmo internacional” y sus supuestas maniobras por medio de la familia minera Guggenheim, del empresario Agustín Edwards Mac Clure y del Ministro de Hacienda Gustavo Ross Santa María -a pesar de que estos dos últimos ni siquiera eran judíos. Según Mundo Judío, los nacistas intentaban instalar artificialmente el problema judío en Chile sobre la base de relacionar al "pueblo o nación judía con la interdependencia mundial originada por el actual sistema capitalista", ignorando "los elementos interconfesionales que rigen en los negocios financieros" y sentando "una premisa absolutamente falsa" respecto del judaísmo (Mundo Judio, 21 febrero 1935, p. 1).

La decisión de responder directa y explícitamente a las provocaciones nacistas se mantendría a lo largo de todo ese año, haciendo que en numerosas ocasiones el semanario sionista denunciara el intento nacista de instalar en Chile el "problema judío". Sin embargo, dicha elección se vería modificada a partir de 1936, año en que la campaña antisemita del MNS alcanzó su punto más álgido, dando lugar a una nueva estrategia. Desde entonces, los encargados del semanario sionista decidieron dejar de responder a los ataques del MNS y optaron por mantener un estricto silencio frente a las provocaciones nacistas. A pesar de que 1936 fue el año en que la campaña antisemita del MNS alcanzó su punto más álgido, el semanario sionista no volvió a referirse a este grupo ni a sus provocaciones entre 1936 y 1938 (Guzmán Castro, 2013, pp. 61-5).

Entre enero de 1936 y junio de 1939 -fecha en que comienza a publicarse el semanario La Patria-, Mundo Judio optó por centrar su atención preferentemente en la situación de los judíos en Europa y en las eventuales actividades de espías alemanes en suelo chileno. Así, por ejemplo, a fines de enero de 1939 felicitó a las autoridades gubernamentales chilenas y a la Policía de Investigaciones por el reciente descubrimiento de una "agencia de propaganda hitlerista que actuaba bajo el disfraz de oficina de turismo" y que, posiblemente con el apoyo económico de comerciantes alemanes residentes en Chile, habría distribuido 
"material impreso contra los judíos". Mundo Judío no se mostraba sorprendido por el hallazgo, pues la colectividad judía chilena siempre había sospechado que la propaganda antisemita que circulaba en el país "era de procedencia nazi-hitlerista". En todo caso, el semanario sionista creía que este asunto no atañía sólo a los judíos, sino a todos los chilenos, pues la experiencia europea reciente dejaba como enseñanza que la violencia totalitaria "comienza con los judíos, pero nunca se sabe cómo terminará” (Mundo Judío, 26 enero 1939 , p. 3).

Sin embargo, el silencio de Mundo Judío frente al antisemitismo de los fascistas chilenos se rompió con la aparición de La Patria, a comienzos de junio de 1939. Desde entonces, y hasta fines de agosto del mismo año, Mundo Judío se refirió o respondió directamente en seis oportunidades al PNF. Casi todas esas respuestas estuvieron a cargo de E. Zofe, quien desde su columna semanal ironizó permanentemente con la falta de originalidad de los redactores del semanario fascista y con el evidente origen extranjero de su campaña. Así, vemos que pocos días después de publicarse el primer número de La Patria este columnista confesó que la lectura del semanario fascista le había "causado gran disgusto. No porque no me guste la "literatura" antisemita. Al contrario, gozo con las imbecilidades de los "escritores" que hacen el antisemitismo. Por supuesto, siempre que estas perlas de la "literatura" tengan algo de ingenio u originalidad", pero para eso "se necesita talento" y era precisamente "esto lo que le falta a los jóvenes "escritores" y "periodistas" antisemitas que en los últimos tiempos han brotado en esta tierra". Según Zofe, el trabajo de los "plumarios antisemitas" de nada servía, pues “¿a quién se va a ocurrir creer al "periodista” de La Patria cuando éste afirma que en el proceso de Berna se comprobó la autenticidad de los Protocolos de los Sabios de Sión”, o “¿quién tomará en serio a un periódico que en su página de redacción afirma que Lenin era judío?”. Por todo lo anterior, Zofe concluía que "con mentiras, tergiversaciones y tonteras que saltan a primera vista no se puede hacer antisemitismo" (Mundo Judio, 8 junio 1939, p. 3).

Siete días después, y bajo el título de "Ocho mil", Zofe volvió a dedicar su columna semanal al antisemitismo de La Patria. El título de la columna se debía a que los fascistas 
chilenos llevaban tiempo enarbolando acusaciones como que "ocho mil judíos de Europa Central están invadiendo Chile en los momentos actuales. Judíos que nadie quiere recibir se radicarán en Chile", o sea, que un pueblo extranjero "se adueñará del país" y "convertirá a los chilenos en verdaderos esclavos". Para Zofe, las cifras que entregaba el semanario fascista eran tan exageradas que desvirtuaban cualquier alegato del PNF sobre el particular, por lo que advertía a sus editores a no aventurarse con cifras, pues "las cifras se desmienten con cifras" y "se puede ser desmentido y lo único que queda es el ridículo". En cualquier caso, cabe destacar que en esta segunda columna dedicada al antisemitismo del PNF, Zofe renuncia por un instante a la ironía y destaca, en la misma línea teórica de nuestra investigación (Guzmán Castro, 2012), que "la cifra 8.000 ha dejado de ser, en este país, una cifra cualquiera. Se ha convertido en un símbolo. Un símbolo doble: de ataques al Gobierno y de campaña antijudía" (Mundo Judío, 15 junio 1939, p. 3).

En su tercera columna dedicada al antisemitismo de La Patria, Zofe se refirió a las acusaciones de "imperialismo judío" que el semanario fascista había vertido recientemente, a propósito de la instalación en Chile de la fábrica de zapatos Bata. La Patria se oponía a la instalación en Chile de esta empresa porque sus dueños eran supuestamente judíos y porque los zapateros nacionales no podrían competir con este "imperialismo judaico". Una vez más, en vez de rebatir directamente las acusaciones de los fascistas chilenos, Zofe prefirió poner énfasis en su falta de originalidad y en el origen extranjero de sus alegatos: "Lo del imperialismo judío es ya una vieja historia. Es la variación del concepto de “judío internacional". Concepto tan usado y abusado en la literatura antisemita, en libros, folletos y periódicos". Según Zofe, "no revela gracia especial, ni ingenio, ni originalidad hablar del imperialismo judío o del judío internacional. No hace ya el efecto deseado. Cae en lo vacío. No impresiona", por lo que concluía su columna de manera similar a las anteriores, advirtiendo a los redactores de La Patria de lo arriesgado que era "atribuir a un no judío el apodo de 'judío' o ‘imperialista judío'. Es muy fácil ser desmentido”, ante lo cual “lo único que queda es el ridículo" (Mundo Judío, 22 junio 1939, p. 3). 
La ironía con que Zofe enfrentó el antisemitismo de La Patria se vio matizada a mediados de julio, cuando criticó la insistencia de los redactores del semanario fascista en contra de la inmigración judía y, nuevamente, la falta de originalidad de sus alegatos: "No importa que [La Patria] sea contrario a los judíos, pero que sea ingenioso". Zofe no duda en calificarlos de "pobres y desvergonzados. Pobres de espíritu, de ingenio, de originalidad; desvergonzados, así a secas", enfatizando luego en que se los debe llamar "desvergonzados, porque mienten a sabiendas, porque tergiversan con toda la premeditación, porque todo lo que dicen es falso. Porque especulan sobre la ignorancia de las masas, porque envenenan al pueblo" (Mundo Judio, 13 julio 1939, p. 3).

Desde entonces, pareció que Mundo Judio aplicaría nuevamente la estrategia con la que enfrentó el antisemitismo nacista entre enero de 1936 y su colapso como partido, a fines de 1938. Es decir, pareció que no volvería a mencionar al PNF ni a su semanario, y que su única respuesta consistiría en el silencio. Sin embargo, a comienzos de agosto volvió a referirse a las actividades del partido de Olivares Maturana con motivo de la presentación del proyecto de ley contra el racismo presentado por los diputados socialistas Latcham y Rossetti $^{3}$, "proyecto de ley tendiente a restringir los excesos de la propaganda antisemita". Zofe expresó entonces su esperanza en que la iniciativa legal fuera aprobada -cosa que, finalmente, no ocurrió- y que a través de ella se pusiera freno a las actividades del PNF, en especial a su intento sistemático de explotar aquel "odio ciego, cerrado, sin argumentación alguna" llamado antisemitismo. Una de las primeras cosas que llamaba la atención de los judíos que por esos días llegaban a Chile, aseguraba Zofe, era la presencia en quioscos de una publicación que "limita con la pornografía", como La Patria, que poco tenía que envidiar a la revista antisemita alemana Der Stürmer, dirigida por Julius Streicher. Por ello, Zofe insistía en la necesidad de que se aprobara el proyecto de ley de los diputados Latcham y Rossetti, pues permitiría poner fin a la "bravata antisemita" de los fascistas chilenos (Mundo Judio, 10 agosto 1939, p. 3).

\footnotetext{
${ }^{3}$ En agosto de 1939, y como una manera de enfrentar los intentos fascistas por instalar en Chile el racismo nazi, los diputados frentistas R. Latcham y J. Rossetti presentaron un proyecto de ley que perseguía como delito cualquier intento por instalar en Chile ideologías que discriminasen sobre la base de la raza (Guzmán Castro, 2012).
} 
La última vez que Zofe se refirió en su columna a La Patria fue a fines de agosto, con motivo de la inclusión en sus páginas del "Talmud (Schuljan Aruj)", texto antisemita de origen alemán que muy difícilmente pudo haber llegado a manos del PNF sin intervención alemana. En la ocasión, el columnista dio una breve reseña histórica del texto en cuestión, dando a conocer su origen y las dudosas credenciales de su autor, así como el rol del partido nazi alemán en la resurrección de este viejo texto antijudío prusiano de fines del siglo XIX. Por supuesto, desacreditaba totalmente las afirmaciones contenidas en él, pues era "un trabajo tendencioso, basado en la falsificación, en la tergiversación, en la malicia". Pero lo más importante de esta columna no era su referencia al pasado del texto, sino las conclusiones a las que llegaba a partir de su presencia en las páginas de La Patria: que a sus redactores se les había acabado el material antisemita "de factura propia" y, sobre todo, que éstos habían entrado "en relaciones directas" con la central antisemita nazi en Erfurt, Alemania, pues habían recibido el texto traducido al castellano. Ciertamente, esta idea no fue considerada ni por Valdivia $(1993,1995)$ ni por Klein $(2000,2001)$ en sus estudios sobre el PNF, pero considerando el material antisemita de origen extranjero contenido en La Patria -caricaturas, artículos, columnas-, la denuncia de Zofe no parece fácilmente descartable (Mundo Judio, 24 agosto 1939, p. 3).

Desde entonces, Mundo Judío no volvió a referirse a La Patria ni a su campaña antisemita. Ni siquiera en noviembre de 1939, cuando la polémica en torno a la concentración fascista organizada por el partido de Olivares Maturana lo puso en el centro de la atención pública. La última vez que un medio de prensa se refirió al PNF fue en junio de 1940, tres meses después de la publicación del último número de La Patria, cuando Mundo Judío denunció que durante las últimas semanas los redactores del "difunto" semanario fascista habían “difundido una circular insultante para los judíos”. Según Chanteclair, autor del artículo y destacado columnista que enfrentó la campaña antisemita de Trabajo a mediados de los años treinta (Guzmán Castro, 2013, pp. 61-5), el panfleto en cuestión era "idéntico, palabra por palabra" a uno publicado en Argentina, lo que vendría a comprobar que la "Quinta Columna" era "una organización internacional, financiada por los nazis y que usa las 
mismas armas ilícitas en todo el continente americano: antisemitismo, seudo-nacionalismo, calumnia, difamación" (Mundo Judio, 7 junio 1940, p. 3).

\section{Conclusiones}

La campaña antisemita desarrollada por el PNF entre la aparición de su semanario, en junio de 1939, y su desaparición de la escena política chilena, a mediados de 1940, fue mucho más agresiva, persistente y sistemática que la de su predecesor, el MNS, logrando gran notoriedad pública. Esta campaña suscitó la reacción de los judíos jóvenes y políticamente activos organizados en torno a la Federación Sionista y el semanario Mundo Judío, reacción que se caracterizó, en primer lugar, por un quiebre con la estrategia que este semanario había adoptado para enfrentar los ataques y provocaciones fascistas, es decir, el silencio sistemático que se había escogido se vio trisado a raíz de la radicalidad de La Patria. Entonces, entre junio y agosto de 1939, el columnista Zofe respondió en múltiples oportunidades al semanario del PNF, casi siempre en forma irónica, burlándose de los fascistas chilenos por su falta de originalidad y por el origen extranjero del material antisemita del que hacían gala. Sin embargo, a partir de septiembre de ese año la estrategia de contención basada en el silencio, en ignorar las provocaciones del PNF para evitar que éstas encontraran eco en la sociedad chilena gracias a la polémica, volvió a aplicarse. A pesar de que entre septiembre y noviembre la campaña antisemita de La Patria alcanzó su punto más radical e incluyó material de evidente origen nazi alemán -como caricaturas de gran calidad, y otras secciones como el Talmud Schuljan Aruj-Mundo Judio se abstuvo de referirse sobre el particular.

La reacción de la prensa sionista -así como de la prensa de izquierda y de la antifascista, que por una cuestión de extensión no podemos incluir en este artículo- pone de manifiesto que el antisemitismo del PNF, expresado principalmente a través del semanario La Patria, no pasó desapercibido en la colectividad judía chilena de la época. Lejos de potenciar el crecimiento del partido y de atraer nuevos militantes a sus filas, la campaña antisemita del PNF tuvo una importancia crucial en el fracaso de su proyecto político, dado el amplio 
rechazo que dicha campaña provocaba en la sociedad chilena, ampliamente informada sobre la violencia sufrida por los judíos en Europa por esos mismos días.

\section{Bibliografía}

\section{Fuentes primarias}

La Patria, junio 1939 - marzo 1940

Mundo Judío, enero 1935 - diciembre 1940

\section{Fuentes secundarias}

Arendt, H. (2004). Los orígenes del totalitarismo. México: Taurus.

Bauman, Z. (1997). Modernidad y Holocausto. Madrid: Sequitur.

Bicheno, H. (1972). Anti-parliamentary Themes in Chilean History, 1920-1970. Government and Opposition, 7(3), 351-388.

Cohn, N. (1983). El mito de la conspiración judía mundial. Los Protocolos de los Sabios de Sión. Madrid: Alianza.

Deutsch, S. M. (1996). Anti-Semitism and the Chilean Movimiento Nacional Socialista. En Sheinin, D. y Barr, L. B. (Eds.). The Jewish Diaspora in Latin America: New Studies on History and Literature (pp. 161-181). Nueva York: Garland. 
Deutsch, S. M. (2005). Las derechas. La extrema derecha en la Argentina, el Brasil y Chile. 1890-1939. Buenos Aires: Universidad Nacional de Quilmes Editorial.

Edwards Vives, A. y Frei Montalva, E. (1949). Historia de los partidos políticos chilenos. Santiago: Pacífico.

Etchepare, J. y Stewart, H. I. (1995). Nazism in Chile: A Particular Type of Fascism in South America. Journal of Contemporary History, 30 (4), 577-605.

Fontaine, A. (1974). Ideas nacionalistas en Chile. En Arce Eberhard, A. y Campos Menéndez, E. (eds.). Pensamiento nacionalista (pp. 233-247). Santiago: Gabriela Mistral.

Germani, G. (1962). Antisemitismo ideológico y antisemitismo tradicional. Criterio, 9, 5563.

Grugel, J. (1985). Nationalists Movements and Fascist Ideology in Chile. Bulletin of Latin American Research, 4 (2), 109-122.

Guzmán Castro, G. (2012). La patria sin judios: antisemitismo nacionalista en Chile, 19321940. Los casos del Movimiento Nacional Socialista y del Partido Nacional Fascista. Tesis de magíster, Universidad de Chile, 236 h.

Guzmán Castro, G. (2013). Al margen del antisemitismo: Respuestas del semanario Mundo Judío al Movimiento Nacional Socialista de Chile (1935-1938), Cuadernos Judaicos, 30, 51-69.

Klein, M. (2000). A Comparative Analysis of Fascist Movements in Argentina, Brazil and Chile between the Great Depression and the Second World War. Tesis doctoral, Universidad de Londres, Londres, Gran Bretaña. 
Klein, M. (2001). The New Voices of Chilean Fascism and the Popular Front, 1932-1938. Journal of Latin American Studies, 33(2), 347-375.

Lvovich, D. (2003). Nacionalismo y antisemitismo en la Argentina. Buenos Aires: Vergara.

Nes-El, M. (2009). Los judíos y su actuación en la política chilena, 1920-1952. En Nes-El, M. Estudios sobre el judaísmo chileno (pp. 67-89). Jerusalén: Revista de Oriente y Occidente.

Pike, F. (1963). Chile and the United States, 1880-1962: The Emergence of Chile's Social Crisis and the Challenge to the United States Diplomacy. Notre Dame: University of Notre Dame Press.

Potashnik, M. (1974). Nacismo: National Socialism in Chile, 1932-1938. Tesis doctoral, Universidad de California, 365 h.

Ramírez Necochea, H. (1978). El fascismo en la evolución política de Chile hasta 1970. Araucaria de Chile, 1, 9-33.

Sznajder, M. (1990). El Movimiento Nacional Socialista: Nacismo a la chilena. Estudios Interdisciplinarios de América Latina y el Caribe, 1 (1), 41-57.

Sznajder, M. (1992). El nacionalsocialismo chileno de los años treinta. Mapocho, 32, 169193.

Valdivia, V. (1993). Las nuevas voces del nacionalismo chileno, 1938-1942. Boletín de Historia y Geografía, 10, 119-139.

Valdivia, V. (1995). El nacionalismo chileno en los años del Frente Popular (1938-1952). Santiago: Universidad Católica Blas Cañas. 